planning in the light of our estimates not only of s.d.'s of navigational error but, more important, of blunder rates.

Returning to Mr. Willis's article $(9,3$ ro), it might be remarked that a system of controlling aircraft which leaves unimpaired a company's strategy of flying optimum path tracks has some attractions. A depression in mid-Atlantic will automatically provide some measure of traffic control, since westerly flying aircraft will choose a northerly, and easterly flying aircraft, a southerly route. May we hope that, in the problem of controlling aircraft across great regions of high traffic density, a good compromise may be reached between the theoreticians with their insistence of very small collision risks and the practical men with their needs not only of safety, but also of economy and simplicity?

\title{
Aircraft Performance Standards
}

$$
\text { from Captain H. L. Lee }
$$

IN his Presidential Address, Captain A. M. A. Majendie emphasizes the value of the Institute in preserving the essential link between theory and practice. Particularly in aviation there is a risk that the ingenuity of the designer will lose value unless it is directly associated with the practical work of the operator. As airborne equipment becomes more complex, the operator cannot hope to grasp more than the fundamentals of much of the theory behind it, and his criticisms must perforce be tentative and somewhat uncertain.

This writer has found considerable concern among other airline route pilots besides himself, about some aspects of aircraft flight performance. The subject was admirably outlined recently by $R$. E. Gillman.* But the present writer suggests that those responsible for the legislation, and those who carried out the research which preceded it, at some stages lost contact with the practical.

As an illustration the reader is asked to consider a case which frequently arises in connection with the Weight Altitude Temperature restrictions. A pilot is at a tropical airfield which is perhaps little more than a strip cut from the undulating bush; it is afternoon, and the temperature is so high, shall we say $35^{\circ} \mathrm{C}$., that he cannot take off. If he did so, and an engine failed, the aircraft would not be able to maintain that 1.9 per cent gradient of climb which the legislation requires. The pilot therefore waits until early evening when, the Sun having set, the temperature falls to the tabulated figure of perhaps $31^{\circ} \mathrm{C}$. The pilot may now proceed to take-off knowing that he is complying with the legislation.

There appear to be two flaws in this procedure. First, many pilots would consider that in the event of an engine failure on take-off, followed by the critical and very shallow climb such as is envisaged, the fact that it is dark will be a far more serious handicap than would be a slightly lower performance. When take-off conditions are not critical, darkness may indeed make little difference. It is precisely when conditions are marginal, especially when there are no ground reference lights, that only exceptional airmanship can obtain from

* Gillman, R. E. (1956). Operational performance standards for civil aircraft. This Journol, 9, 436 . 
the aircraft the optimum climb of which it is capable. Secondly, the legislation does not take into account temperature inversion above the ground. In the example quoted, the temperature at 300 feet might be $5^{\circ} \mathrm{C}$. higher than on the ground. The writer doubts whether the legislation makes adequate allowance for this, and understands that one British operator already allows for such an inversion in certain cases. Such an allowance could restrict take-off weight by over a thousand pounds.

If these are indeed flaws in the legislation, what are we to think of the remainder? The Performance Regulations in the appropriate Statutory Instrument comprise nine pages, and include some sentences of great length, exceeding 300 words, which are made ambiguous by poor punctuation. The writer will confine comment to a half-dozen of the points in the Performance Group A Regulations which, whilst not necessarily wrong, appear suspect in the eyes of the operator.

I. Take-off calculations are not based, as one would expect, on density altitude, but on a compounding of temperature with actual airfield altitude. Perhaps the thought underlying this, was that, when there is a high limiting temperature, pressure is unlikely to be far from standard. However, circumstances can be envisaged when this assumption would be quite false.

2. In calculations of take-off run, \&c., runway gradient is taken into consideration, but only the average gradient over each of the three critical distances. Yet 'hump-backed' runways do exist, and make nonsense of the calculations.

3. In both take-off and landing calculations, an allowance is made for the factored wind component along the runway. No allowance is made for cross-wind component. Yet an aircraft, which takes-off whilst there is a $25 \mathrm{kt}$. wind across the runway, might be expected to have its run extended.

4. In calculations to determine whether obstacles are in the path of the aircraft after take-off, a formula using three components is used. Despite this, should an aircraft experience $10^{\circ}$ of drift, or wander off heading by the same amount, it might encounter obstacles deemed by the formula to be outside its path.

5. The writer is uneasy about the definition of take-off emergency distance, better named accelerate-stop distance. Part of the aircraft's braking run is to take place over surface which is 'incapable of bearing (its) weight under normal operating conditions'. What is more questionable, is that there appears to be no requirement for this to be lit at night.

6. The Regulations concerning landing distance appears to be based on a weight calculated before take-off. No allowance appears to be made for the contingency of an aircraft making an earlier and consequently heavier arrival.

The purpose of this note is not in any way to belittle the value of the legislation which, as R. E. Gillman remarked, cannot in any case replace airmanship. The writer's prime concern is not so much to suggest that the Regulations are faulty as to express the widely held view that they could be improved upon. The vast amount of work which went into the I.C.A.O. report which preceded the Regulations has given pilots a valued protection. But cooperation between 
theorists and operators, through such media as the Institute, might well improve the legislation.

$$
\text { from M. Gwin }
$$

I READ with interest Captain Gillman's excellent paper on performance standards for 'A' category aircraft.

At the risk of 'splitting hairs' I feel that one point may well have caused confusion to those readers unfamiliar with the type of performance graphs illustrated.

Captain Gillman refers to the extraction of $V_{1}$ speeds from the emergency distance, take-off distance and take-off run graphs, for the purpose of cross plotting against various weights in order to obtain optimum $V_{1}$ speed.

Inspection of the graphs reproduced as Figs. I and 3 will show that in fact a direct $V_{1}$ speed is not extracted but rather a ratio of $V_{1} / V_{2}$ speeds. In my experience, normal practice is to extract $V_{1} / V_{2}$ ratios and plot a series of ratios against all-up weight. That is, as shown in Fig. 4 but reading $V_{1} / V_{2}$ rather than $V_{1}$ speed in knots. Having determined maximum T.O.W. from this plot, the $V_{1}$ speed at this weight can be determined by application of the appropriate $V_{1} / V_{2}$ ratio. $V_{2}$ speed is determined from the flight manual by reference to weight only; having found $V_{2}$, application of the ratio gives $V_{1}$.

\section{Captain R. E. Gillman comments :}

I agree entirely with Captain Lee's remarks on the inadequacy of the existing legislation. It does need amplification on certain issues, but one must bear in mind, that no amount of regulations can replace sound airmanship, and the complication resulting from an attempt to cover all flight contingencies, would negate the advantages in so doing.

What is essential I think, is that pilots should have a good background knowledge of the rational concepts so that they can apply the system intelligently should circumstances exist which fall outside their present scope.

Actual $V_{1}$ speeds were used in the take-off weight plot for purposes of clarity, for it makes no difference to the result if $V_{1} / V_{2}$ ratios are converted to speeds, before or after the plot.

\section{Mariner's Astrolabes \\ from Commander W. E. May, R.N. \\ (National Maritime Museum)}

IN Dr. Derek Price's most interesting article 'Two Mariner's Astrolabes'* he suggests that the heyday of this instrument was from 1530 to 1630 . Some additional light is thrown on the closing date of the period of use of the astrolabe

* This Journal, 9, 338 . 